1. BDS, FCPS (Orthodontics) Assistant Professor de'Montmorency College of Dentistry,

Lahore, Pakistan

2. BDS, FCPS (Oral \&Maxillofacial Surgery)

Associate Professor

Department of Oral \& Maxillofacial

Surgery

Faisalabad Medical University,

Faisalabad, Pakistan.

3. BDS

House Officer

Punjab Dental College Lahore.

4. BDS

PG Trainee

Department of Orthodontics de'Montmorency College of

Dentistry,

Lahore, Pakistan

Correspondence Address:

Dr. Muhammad llyas

de'Montmorency College of Dentistry,

Lahore, Pakistan.

m_ilyas08@yahoo.com

Article received on:

15/03/2019

Accepted for publication:

19/05/2019

Received after proof reading:

22/05/2019

\section{ORAL HYGIENE AWARENESS IN ORTHODONTIC PATIENTS; A CROSS SECTIONAL SURVEY.}

\begin{abstract}
Muhammad Ilyas' ${ }^{1}$, Muhammad Usman Khalid ${ }^{2}$, Syeda Qurrat-Ul-Ain Arif ${ }^{3}$, Sobia Ashraf ${ }^{4}$
ABSTRACT... To evaluate the current status of oral hygiene awareness in patients undergoing active orthodontic treatment and to educate them how they can improve and maintain their oral health throughout orthodontic treatment to minimize the risk of dental caries, plaque deposition, gingivitis and localized enamel decalcification. Study Design: Prospective survey. Setting: Orthodontic Department, Punjab Dental Hospital Lahore, Pakistan. Period: 06 months $1^{\text {st }}$ August 2018 to $31^{\text {st }}$ January 2019. Materials and Methods: A structured questionnaire was distributed to 100 patients undergoing active orthodontic treatment at orthodontic department of Punjab Dental Hospital Lahore, Pakistan in an effort to assess the level of awareness and practical measures taken by patients to maintain and improve their oral health during orthodontic treatment. Results: 100 patients undergoing active orthodontic treatment of 10 to 25 years old age group were randomly selected at orthodontic department of Punjab Dental Hospital, Lahore. Conclusion: This survey revealed that most of the patients are aware and practising oral hygiene measures during their orthodontic treatment and dentist should repeat all these instruction on every visit.
\end{abstract}

Key words: $\quad$ Oral Hygiene, Orthodontic Patients, Malocclusion, Gingivitis.

Article Citation: Ilyas M, Khalid MU, Arif SQ, Ashraf S. Oral hygiene awareness in orthodontic patients; A cross sectional survey. Professional Med J 2019; 26(6):10001004. DOI: 10.29309/TPMJ/2019.26.05.3574

\section{INTRODUCTION}

Malocclusion is one of major dental and oral health problems after dental caries and periodontal diseases. It is a predisposing factor for many TMJ problems, periodontal diseases, speech problems, mouth breathing, inadequate oral hygiene and many other problems. ${ }^{1}$

In this advanced age, a great proportion of young population is demanding orthodontic treatment. Orthodontic treatment aims to provide a stable occlusal relationship and pleasant aesthetics with healthy masticatory function.

However, while addressing this basic issue certain other oral health problems can also develop i.e Gingivitis ${ }^{2-4}$ due to increased incidence of plaque deposition as the oral hygiene maintenance becomes more difficult in the presence of fixed orthodontic appliances in the oral cavity, severe gingivitis may lead to loss of gingival attachment ${ }^{5}$ and gingival recession.
Gingival enlargement occurring during orthodontic treatment with fixed appliances may progress to formation of pseudo pockets. In this case, there is no gingival enlargement but hyperplasia of gingival tissue results in formation of an artificially deep pocket. ${ }^{6}$

Patients undergoing orthodontic treatment show greater values of plaque index, bleeding index and pocket depth than normal baseline values. ${ }^{7}$

Orthodontic patients are more prone to develop dental caries because of an overall increase in Lactobacilli count in saliva and Spirochete and Fusiform bacteria count in sub gingival oral flora. Different species of anaerobic bacteria like Bacterioids intermedius, Spirochetes, B.forsythus, Denticola, P.nigrescens , C.rectus and fusiform bacteria increase more frequently in the dental plaque of patients undergoing orthodontic treatment. ${ }^{8}$ 
White spot lesions; a well-known side effect of orthodontic treatment in patients with poor oral hygiene. ${ }^{9}$ In fact the lesions represent localized decalcification, can progress from white spots to carious lesions. Fixed orthodontic appliances and bonding materials enhance the retention of salivary biofilm and thus increase the risk of white spot formation.

Patients undergoing orthodontic treatment are prone to develop oral ulcerations particularly when arch wires, bands, brackets and long unsupported stretches of wires rest against the lips. Excessive muscular activities of cheek and tongue may also act as a trigger factor for ulceration. ${ }^{10,11}$

In an effort to make orthodontic treatment successful and to minimize the risk of oral health problems associated with it, awareness as well as practical measures taken by the patients are essential to maintain and improve their oral health.

\section{Selection Criteria for Study}

100 patients undergoing active orthodontic treatment of 10 to 25 years old age group were randomly selected at orthodontic department of Punjab Dental Hospital, Lahore meeting the following criteria;

1. Treatment that consisted of full-mouth fixed orthodontic appliances that had been in place for at least six months.

2. No systemic diseases.

3. No history of taking antibiotics for the last three months.

Information about the patient's oral hygiene practices was obtained using a questionnaire designed to be comprehensive for all patients. The study did not obtain any confidential demographic information such as income or educational level.

\section{Questionnaire AboutOralHygieneAwareness In Orthodontic Patients}

1. Do you use Tooth Brush?

a. Yes b- No

If yes, how many times do you use it daily?

a. 1 Time b- 2 Times c- 3 Times d- Irregularly
Which type of Tooth brush do you use?

a. Soft b-Medium c- Hard d-Any type available

2. Other than brushing, do you take extra measures to improve your oral health?

a. Yes b- No

If yes, which of the following oral hygiene aids do you employ?

a. Dental floss b- Miswak c- Tooth Pick d- Inter dental Brush

3 Have you used mouthwash since your orthodontic treatment?

a. Yes b- No

If yes, how frequently do you use it?

a. Once Daily b- Twice Daily c- Before going to your dentist

d- When your dentist prescribes it to treat your swollen gums.

Which type of Mouthwash do you use?

a. Fluoridated b- Non-Fluoridated c- Any type available d- have no idea

4. Have your dentist told you not to eat Sticky Foods?

a. Yes b- No c- I do not remember.

Do you eat Sticky Food during orthodontic treatment?

a. Yes, frequently b- Yes, Sometimes c- Not at all.

5. Have you visited Periodontal Department for scaling during orthodontic treatment?

a. Yes b- No

If yes, how many times have you visited?

a. One at the start of orthodontic treatment

b. At regular intervals to maintain the good health of gums

c. Off and on when dentist suggests you.

\section{RESULTS}

\section{Tooth Brush and Brushing Frequency}

All patients reported using a manual tooth brush for cleaning their teeth. Sixteen patients reported brushing their teeth once daily, Forty six patients said that they brush twice daily, twenty nine patients brushed thrice daily whereas only nine patients out of hundred reported of brushing irregularly. The following graph shows frequency of brushing per day. 


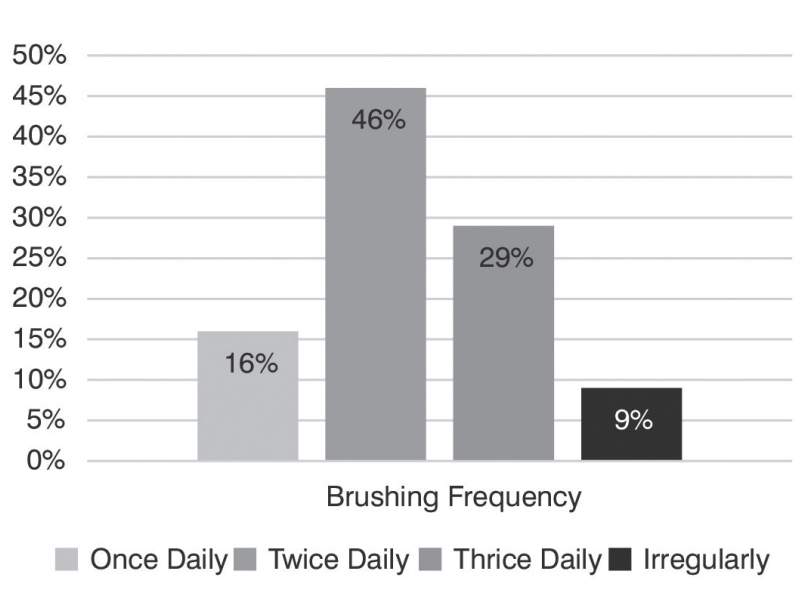

\section{Types of Toothbrush Used for Brushing}

Forty one patients reported of using soft toothbrush for cleaning their teeth, forty four patients were using medium toothbrush, only two patients were using hard type tooth brush whereas thirteen patients were not careful about specific type of toothbrush, they were using any type of brush available in market.

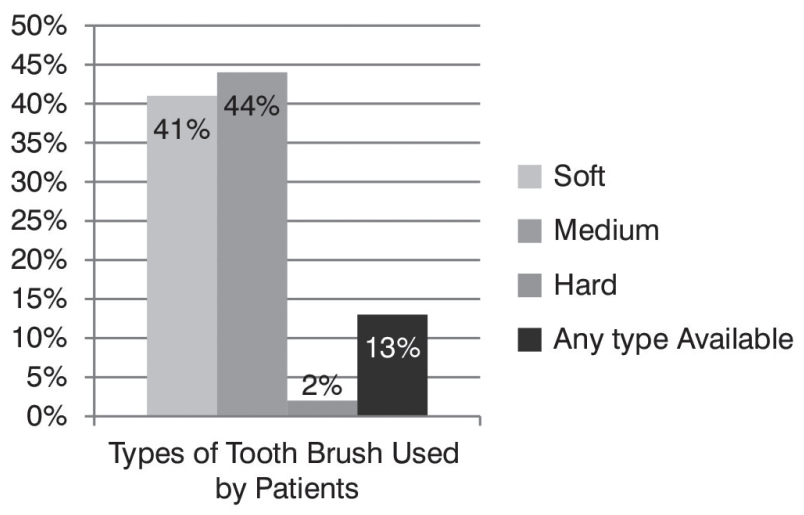

\section{Brushing Technique}

The evaluation of brushing techniques revealed that eight patients were using a circular movement, forty four patients used a horizontal movement, and twenty six patients were using a vertical movement in one direction. The remaining twenty two patients were unable to describe their method of brushing, so their technique was considered as irregular.

\section{Use of Mouthwash}

Out of one hundred patients in this study, sixty six patients reported of using mouthwash. Among them sixteen patients were using once daily and thirty seven patients reported of using mouthwash twice daily. Eight patients used mouthwash when their dentist recommended it to treat their swollen gums whereas five patients said that they use mouthwash just before going to their dentist.

Among those who were using mouthwash, only eleven patients were using fluoridated mouthwash, thirty-one patients were using nonfluoridated mouthwash whereas twenty-four patients had no idea which type of mouthwash they were using.

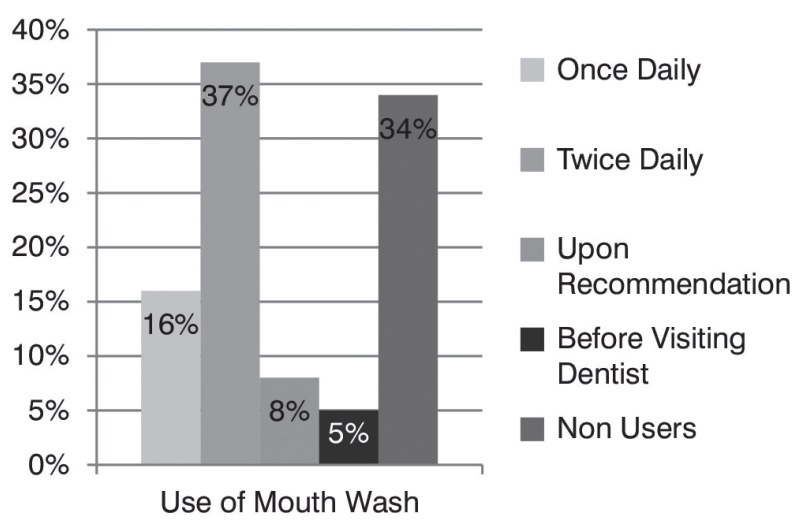

\section{Use of Additional Oral Hygiene Aids}

During this survey, sixty three patients stated that they were employing additional oral hygiene aids other than manual toothbrush or mouthwash. Fifty two patients were using inter dental brush, seven patients were using tooth pick and four patients were using dental floss to remove food debris once it got stuck in teeth or around brackets.

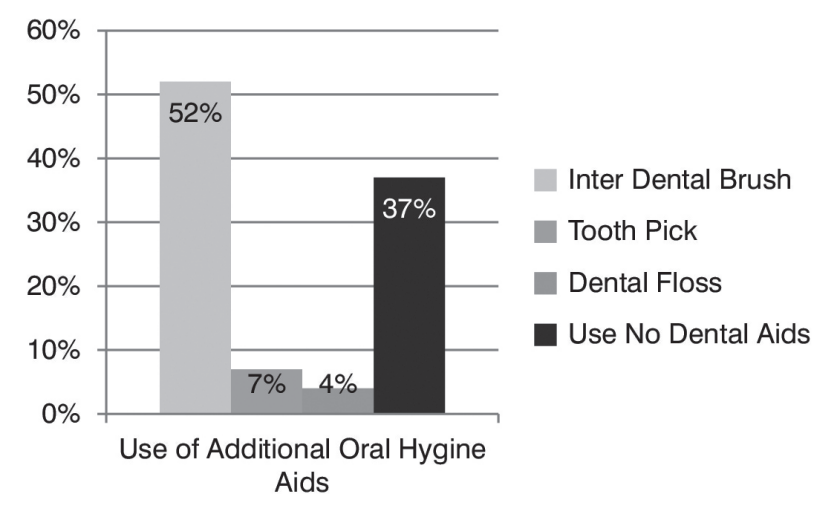

\section{Consumption of Sticky Foods}

The patients being surveyed are questioned about sticky food consumption. Out of one hundred patients, seventy four patients were 
told by their dentists not to eat foods which tend to stick and consequently increase the risk of plaque deposition and dental caries many folds. Four patients were not given such instructions, whereas twenty two patients do not remember whether they were given such guidelines or not.

Thirty six patients strictly follow the instructions and don't eat sticky foods. Fifty seven patients eat such foods occasionally whereas seven patients reported to eat sticky foods frequently.

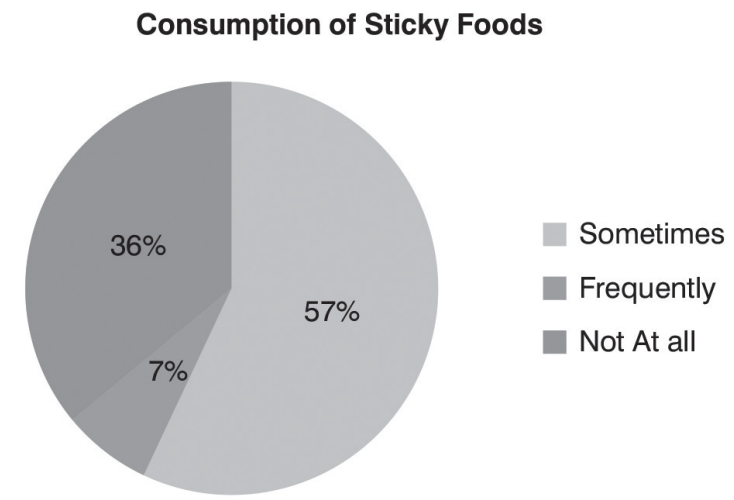

\section{Visit to Periodontal Department for Scaling}

During orthodontic treatment, seventy eight patients had visited periodontal department for scaling. Among them fifty two patients had scaling of their teeth once at the start of orthodontic treatment whereas twenty six patients had scaling for two or more times

On the suggestion of their dentist. Twenty two patients had good oral health so they had scaling done neither before the start of treatment nor during treatment.

\begin{tabular}{|c|c|c|}
\hline $\begin{array}{c}\text { Scaling Once at } \\
\text { Start of Treatment }\end{array}$ & $\begin{array}{c}\text { On Dentist } \\
\text { Suggestion }\end{array}$ & $\begin{array}{c}\text { No Scalling } \\
\text { Done }\end{array}$ \\
\hline $52 \%$ & $26 \%$ & $22 \%$ \\
\hline
\end{tabular}

\section{CONCLUSION}

The survey reveals that majority of patients are aware and practicing oral hygiene measures during orthodontic treatment but not at optimal levels. Dentists should repeat oral hygiene instructions to his patients at every visit especially about the use of interdental brush, fluoridated mouthwash and not to use sticky foods. It's the need of hour to institute oral health awareness programs at regular intervals to motivate the patients, let them perform oral hygiene measures regularly to get an optimal success rate.

Copyright@ 25 May, 2019.

\section{REFERENCES}

1. R Glans, E Larsson, B Ogaard. Longitudinal changes in gingival condition in crowded and noncrowded dentitions subjected to fixed orthodontic treatment. Am J Orthod Dentofacial Orthop. 2003; 124:679-682.

2. Zachrisson S, Zachrisson BU. Gingival condition associated with orthodontic treatment. Angle Orthod. 1972; 42(1):26-34.

3. Leggott PJ, Boyd RL, Quinn RS, Eakle WS, Chambers DW. Gingival disease pattern during fixed orthodontic therapy adolescents versus adults. J Dent Res 1984; 63 (Special issue): 309, abstract 1245.

4. Huser MC, Baehni PC, Lang R. Effects of orthodontic bands on mirobiologic and clinical parameters. Am J Orthod Dentofacial Orthop.1990; 97(3):213-8.

5. Zachrisson BU, Alnaes L. Periodontal condition in orthodontically treated and untreated individuals. I. Loss of attachment, gingival pocket depth and clinical crown height. Angle Orthod. 1973; 43(4):402-11.

6. Chang HS, Walsh LJ, Freer TJ. The effect of orthodontic treatment on salivary flow, $\mathrm{pH}$, buffer capacity, and levels of mutans streptococci and lactobacilli. Aust Orthod J. 1999; 15(4):229-34.

7. S Alstad, BU Zachrisson. Longitudinal study of periodontal condition associated with orthodontic treatment in adolescents. Am J Orthod. 1979:133151.

8. Paolantonio $M$, Pedrazzoli V, di Murro $\mathrm{C}$, di Placido G, Picciani C, Catamo G, De Luca M, Piaccolominir. Clinical significance of Actinobacillus actinomycetemcomitans in young individuals during orthodontic treatment. A 3-year longitudinal study. J Clin Periodontol. 1997; 24(9 Pt 1):610-7.

9. Preventing and treating white-spot lesions associated with orthodontic treatment: A survey of general dentists and orthodontists. Department of Orthodontics, School of Dentistry, Virginia Commonwealth University, Richmond, VA 23298, USA. hamdanama@hotmail.com. 
10. Profit WR (2007) Orthodontic treatment planning: Limitations, Controversies and special problems. Contemporary Orthodontics (4th edtn) Elsevier Science: 268-330.

11. Anhoury P, Nathanson D, Hughes CV, Socransky S, Feres M, et al. (2002) Microbial profile on metallic and ceramic bracket materials. Angle Orthod 72: 338-343.
12. SA Alexander. Effects of orthodontic attachments on the gingival health of permanent second molars. Am J Orthod Dentofacial Orthop. 1991; 100(4):337-340.

13. BU Zachrisson, S Zachrisson. Caries incidence and oral hygiene during orthodontic treatment. Scand $\mathrm{J}$ Dent Res. 1971; 79(6):394-401.

\begin{tabular}{|c|l|l|l|}
\hline \multicolumn{3}{|c}{ AUTHORSHIP AND CONTRIBUTION DECLARATION } \\
\hline Sr. \# & \multicolumn{1}{|c|}{ Author-s Full Name } & \multicolumn{1}{|c|}{ Contribution to the paper } & Author=s Signature \\
\hline 1 & Muhammad Ilyas & $\begin{array}{l}\text { Conception of idea, data } \\
\text { collection and script writing. } \\
\text { Data compiling, data } \\
\text { analysis and assistance in } \\
\text { script writing. } \\
\text { Data collection and proof } \\
\text { reading. } \\
\text { Data collection and help in } \\
\text { discussion writing. }\end{array}$ \\
\hline 4 & Sobia Ashraf & Syeda Qurrat-Ul-Ain Arif & Surat \\
\hline
\end{tabular}

